\title{
Myopathy caused by polymyxin E: functional disorder of the cell membrane
}

\author{
M. VANHAEVERBEEK, M. ECTORS, L. VANHAELST, AND L. FRANKEN
}

From the Department of Internal Medicine, Saint-Pierre University Hospital, Brussels, Belgium

SYNOPSIS A myopathy caused by the activity of polymyxin E on the cell membrane was accompanied by immunological manifestations. There were also disturbances of the central nervous system, contrasting with the absence of serious renal lesion.

Polymyxin E (Colistin) is one of the polypeptide antibiotics produced by the soil parasite Bacillus polymyxa (Garrod and O'Grady, 1968) and is characterized by a remarkable activity against Gram negative bacteria (Fekety et al., 1962). Polymyxin E and its sodium methanesulphonate derivative (CMS) are known for their potential toxicity at the renal (Vic-Dupont et al., 1965) and neuromuscular (Lindesmith et al., 1968) levels. It is the aim of the present work to report the case of a man who, treated with large doses of CMS, presented with unusual neuromuscular manifestations.

\section{CASE HISTORY}

The patient, a male aged 66 years, was admitted to the hospital in a state of confusion. His past history revealed recurrent bronchitis, chronic pancreatitis, and the existence two months before the admission of a Klebsiella pneumoniae osteomyelitis of the left capitulum tibiae. This osteomyelitis was treated by surgery and, in addition, by a combination of cotrimoxazole and CMS, the latter administered intramuscularly at a dose of $6 \cdot 10$ mega units daily $(450 \mathrm{mg} / 24 \mathrm{hr}$ ). Cotrimoxazole was discontinued after 40 days, while the CMS treatment was stopped after 60 days, with the beginning of the affection responsible for the admission. It had its onset with diarrhoea; 48 hours later the patient developed total ophthalmoplegia and flaccid paralysis of both upper limbs. The myotatic reflexes were present, and neither sensory deficits nor fasciculation could be found. There were neurological disturbances indicating a frontal syndrome: reduced speech fluency, diminished spontaneous expression, difficulty in finding words, conceptual language difficulties, memory inconsistencies about recent events, apathy, affective indifference without euphoria or disinhibition of instinctive behaviour. In view of this clinical situation and the existence of inflammatory signs, the possibility was considered of multiple cerebral abscesses in the lower motor regions as well as in the prefrontal lobes. This could be excluded by normal results of brainscan, bilateral carotid arteriography, and lumbar puncture. A cervical medullary lesion was excluded, as was a toxic neuropathy, in view of the persistence of the myotatic reflexes and, to a lesser degree, in view of the absence of sensory deficits. The electroencephalogram (EEG) was characterized by slow waves, 6 to $7 \mathrm{~Hz}, 5$ to $20 \mu \mathrm{V}$, generalized over both hemispheres. Electromyography disclosed a primary myopathy. The tracing from the paralysed muscles revealed an interference pattern on minimal contraction. The motor unit action potentials had a voltage between 500 and $700 \mu \mathrm{V}$; they were occasionally polyphasic. No spontaneous electrical activity was recorded. Repetitive supraliminar stimulation of the median nerve at the elbow at $3 \mathrm{~Hz}$ brought about no decrement even after sensitizing with ischaemia. The motor nerve conduction velocity was normal for the median and ulnar nerves $(52 \mathrm{~m} / \mathrm{s})$. Muscle biopsy was normal. Renal function was carefully investigated: blood urea levels were always less than 50 $\mathrm{mg} / \mathrm{dl}$, and serum creatinine levels always less than $1.1 \mathrm{mg} / \mathrm{dl}$; albuminuria was never present, but microscopic haematuria and some granular cylinders were noted. The blood ionograms were always normal. There was a leucocytosis of $21,000 / \mathrm{mm}^{3}$, with $83 \%$ eosinophils. The serum complement level was normal. Immunoelectrophoresis revealed high IgA $(500 \mathrm{mg} / \mathrm{dl})$ and IgG $(2,500 \mathrm{mg} / \mathrm{dl})$ levels. A positive immunofluorescent reaction could be demonstrated against striated muscle fibres 
exposed successively to the patient's serum and to a fluorescent human gammaglobulin antiserum; however, the technique did not allow characterization of the cell component involved in the antigen-antibody reaction. The evolution of the illness was slowly favourable; mental difficulties disappeared after a few days; EEG returned to normal; motor troubles improved slowly and, after three months, the only remaining paresis was in the small hand muscles, the extensor digitorum muscles and the left deltoid. One year after the acute attack, the patient was asymptomatic. The sole explanation for these manifestations is the toxicity of CMS.

\section{DISCUSSION}

This case is an illustration of a particular aspect of the toxicity of CMS, characterized by a myopathy which is described for the first time. Usually the neurological manifestations are peribuccal paraesthesiae, pareses of the head, limb or trunk musculature, extrapyramidal and cerebellar syndromes, and psychiatric manifestations (Richet et al., 1962). The polymyxins are also known for their aggravating action in myasthenia gravis (Decker and Fincham, 1971) and for the danger of respiratory arrest when they are used in conjunction with curarizing compounds in anaesthesiology (Weill et al., 1968). Experimentally, polymyxins have indeed a paralysing action, which, in contrast with the curarimetic effect of the neomycin group antibiotics, cannot be antagonized by neostigmine and calcium. In these experiences, however, CMS unlike polymyxin $\mathrm{E}$, does not have a paralysing action; this fact is explained by the rapid renal elimination of the product (Adamson et al., 1960). Electromyography and stimulo-detection studies reported hitherto are normal (Richet et al., 1962; Gold and Richardson, 1966). Finally, two authors have administered edrophonium: in one of the cases, a partial amelioration of the clinical picture was noted (Gold and Richardson, 1966); in the other, no response was observed (Parisi and Kaplan, 1965). The neurological manifestations can be independent of the dose and appear without any previous renal insufficiency; normal serum levels of CMS confirm this clinical impression. Nevertheless, renal insufficiency is a condition favourable to neurological manifestations of intoxication due to CMS (Wolinsky and Hines, 1962). The general explanation for the neurological disturbances is based on polymyxin's mode of action. It is a cationic detergent which destroys or modifies the lipid compounds of the cell membrane (Carter and McCarty, 1966). The high lipid content of the neurones explains therefore why they are frequently attacked; experimentally indeed a selective binding of polymyxin $\mathrm{E}$ in the brain is observed; the antibiotic accumulates only after repeated administration, especially in the muscles (Kunin and Bugg, 1971). The myopathy described here can be explained either by a direct lesion of the muscular membrane, or by an immunological mechanism due to membrane modifications. The presence of anti-muscle antibodies and of high IgA and IgG levels favours the latter hypothesis. The high blood eosinophil level present here has sometimes been observed (Koch-Weser et al., 1970) indicative of a massive release of mast cell histamine. It may represent either an antigenantibody reaction, or be the result of the direct action of polymyxin $E$ which is a mastocyte 'discharger' (Selye et al., 1964). In conclusion, since CMS remains a first choice antibiotic because of its activity against Gram negative bacteria, its frequent toxicity in man must be taken into account. The toxic reactions observed have a variable evolution. The myopathy regresses slowly, therefore the administration of CMS should be limited to indisputable bacteriological and clinical indications.

\section{REFERENCES}

Adamson, R. H., Marshall, F. N., and Long, J. P. (1960). Neuromuscular-blocking properties of various polypeptide antibiotics. Proceedings of the Society of Experimental Biology and Medicine, 105, 494-497.

Carter, W., and McCarty, K. S. (1966). Molecular mechanisms of antibiotic action. Annals of Internal Medicine, 64, 1087-1113.

Decker, D. A., and Fincham, R. W. (1971). Respiratory arrest in myasthenia gravis with colistimethate therapy. Archives of Neurology, 25, 141-144.

Fekety, F. R., Jr, Norman, P. S., and Cluff, L. E. (1962). The treatment of gram-negative bacillary infections with colistin. Annals of Internal Medicine, 57, 214-229.

Garrod, L. P., and O'Grady, F. (1968). Polymyxins. In Antibiotic and Chemotherapy, 2nd edn, pp. 178-179. Livingstone: Edinburgh.

Gold, G. N., and Richardson, A. P., Jr (1966). An unusual case of neuromuscular blockade seen with therapeutic blood levels of colistin methanesulfonate (Coly-Mycin). American Journal of Medicine, 41, 316-321.

Koch-Weser, J., Sidel, V. W., Federman, E. B., Kanarek, P., Finer, D. C., and Eaton, A. E. (1970). Adverse effects of sodium colistimethate. Annals of Internal Medicine, 72, 857-868. 
Kunin, C. M., and Bugg, A. (1971). Binding of polymyxin antibiotics to tissues: the major determinant of distribution and persistence in the body. Journal of Infectious Diseases, 124, 394-400.

Lindesmith, L. A., Baines, R. D., Jr, Bigelow, D. B., and Petty, T. L. (1968). Reversible respiratory paralysis associated with polymyxin therapy. Annals of Internal Medicine, 68, 318-327.

Parisi, A. F., and Kaplan, M. H. (1965). Apnea during treatment with sodium colistimethate. Journal of American Medical Association, 194, 298-299.

Richet, G., Ardaillou, R., and Sultan, Y. (1962). Accidents neuro-psychiques chez des urémiques chroniques traités par le méthane-sulfonate de colistine. Bulletins et Mémoires de la Société Médicale des Hôpitaux de Paris, 113, 11991205.

Selye, H., Tuchweber, B., and Caruso, P. L. (1964). Protection against neurotropic mastocalcergy. Experimental Neurology, 10, 451-461.

Vic-Dupont, Monsallier, J.-F., Vachon, F., and Rochant, $\mathbf{H}$. (1965). Incidences rénales des traitements par le méthanesulfonate de colistine [M.S.C.]. Bulletins et Mémoires de la Société Médicale des Hôpitaux de Paris, 116, 25-37.

Weill, M., Gauthier-Lafaye, J.-P., and Dupuis, J. (1968). Action curarisante des antibiotiques et potentialisation des curares par les antibiotiques. Therapie, 23, 879-884.

Wolinsky, E., and Hines, J. D. (1962). Neurotoxic and nephrotoxic effects of colistin in patients with renal disease. New England Journal of Medicine, 266, 759-762. 